06

\title{
Магнитные и радиопоглощающие свойства поликристаллического феррита-шпинели $\mathrm{Li}_{0.33} \mathrm{Fe}_{2.29} \mathrm{Zn}_{0.21} \mathrm{Mn}_{0.17} \mathrm{O}_{4}$
}

\author{
() И.М. Исаев, В.Г. Костишин, В.В. Коровушкин, Д.В. Салогуб, Р.И. Шакирзянов, А.В. Тимофеев, \\ А.Ю. Миронович
}

Национальный исследовательский технологический университет „МИСиС“, 119049 Москва, Россия

e-mail: drvgkostishyn@mail.ru

Поступило в Редакцию 22 марта 2020 г.

В окончательной редакции 28 апреля 2020 г.

Принято к публикации 29 апреля 2020 г.

Методом керамической технологии при температурах спекания 950, 1000, 1050 и $1100^{\circ} \mathrm{C}$ синтезированы поликристаллические ферриты-шпинели состава $\mathrm{Li}_{0.33} \mathrm{Fe}_{2.29} \mathrm{Zn}_{0.21} \mathrm{Mn}_{0.17} \mathrm{O}_{4}$. В диапазоне магнитных полей $-400-+400 \mathrm{~A} / \mathrm{m}$ изучены петли магнитного гистерезиса и магнитная проницаемость объектов исследования. В диапазоне частот $0.01-7.0 \mathrm{GHz}$ исследовано поведение комплексной диэлектрической и комплексной магнитной проницаемости, а также коэффициента отражения на металлической пластине. Установлено, что оптимальным диапазоном температур спекания для синтезированных ферритов является диапазон от 1050 до $1100^{\circ} \mathrm{C}$. Показано, что феррит-шпинель $\mathrm{Li}_{0.33} \mathrm{Fe}_{2.29} \mathrm{Zn}_{0.21} \mathrm{Mn}_{0.17} \mathrm{O}_{4}$ интенсивно поглощает электромагнитное излучение в области частот $0.05-7.0 \mathrm{GHz}$. Обсуждены возможности практического применения полученных результатов.

Ключевые слова: феррит-шпинель, литиевый феррит, магнитная проницаемость, радиопоглощение, магнитные свойства.

DOI: $10.21883 / J T F .2021 .09 .51217 .74-21$

\section{Введение}

Литиевые сложнозамещенные ферриты-шпинели нашли широкое применение в качестве рабочих сред электромагнитных и микроволновых устройств, устройств автоматики и запоминающих устройств $[1,2]$. В диапазоне частот от 1 до $100 \mathrm{MHz}$ данные материалы обладают высокими значениями магнитных характеристик, высоким удельным сопротивлением и незначительной магнитострикцией [1]. Интерес к этим материалам обусловлен не только их известными характеристиками, но и возможностью их регулирования и модификации посредством изоморфных замещений $[3,4]$. Группа сложнозамещенных ферритов на основе литиевого феррита относится к высокотермостабильным ферритам [2]. Эти материалы кристаллизуются в кристаллической структуре обращенной шпинели $\mathrm{AB}_{2} \mathrm{O}_{4}$, где А и В обозначают узлы решетки, тетраэдрически и октаэдрически координированные ионами кислорода соответственно. Сверхобменное взаимодействие ионов $\mathrm{Fe}^{3+}$ в подрешетках А и В приводит к ферримагнитному упорядочению магнитных моментов с высокими значениями температуры Кюри-Вейсса и намагниченности насыщения при комнатной температуре [2]. В работах [3-7] показано, что LiZn-ферриты обладают хорошими радиопоглощающими свойствами и могут использоваться в качестве эффективных поглотителей электромагнитных волн СВЧ-диапазона в области частоты одного-нескольких GHz. Авторами работ [6-10] показа- но, что никель-цинковый феррит-шпинель и литиевый феррит-шпинель характеризуются радиопоглощением в области частот $15-18 \mathrm{GHz}$.

Целью настоящей работы было получение и исследование магнитных и радиопоглощающих свойств поликристаллических ферритов-шпинелей $\mathrm{Li}_{0.33} \mathrm{Fe}_{2.29} \mathrm{Zn}_{0.21} \mathrm{Mn}_{0.17} \mathrm{O}_{4}$, изготовленных при разных температурах спекания $\left(T_{S}\right)$ методом керамической технологии.

\section{1. Объекты исследования и методики экспериментальных исследований}

На рис. 1 представлена технологическая схема получения объектов исследования настоящей работы. В качестве исходных материалов использовались оксиды металлов класса ХЧ. Перед измельчением в шихту вводилась легирующая добавка в виде мелкодисперсного порошка $\mathrm{Bi}_{2} \mathrm{O}_{3}$ в количестве $0.2 \%$ mass. Оксид висмута как легкоплавкая добавка активирует спекание за счет формирования диэлектрической прослойки по границам зерен. Кроме того, при использовании $\mathrm{Bi}_{2} \mathrm{O}_{3}$ наблюдается улучшение однородности феррита, повышение его плотности [9-13], а также предотвращение чрезмерного испарения лития и цинка в процессе спекания [13-15].

Ферритизация шихты осуществлялась при температуpe $850^{\circ} \mathrm{C}$. Спекание образцов проводилось в резистивной печи на воздухе при нормальных атмосферных условиях при четырех значениях температуры: 950, 1000, 1050 и 


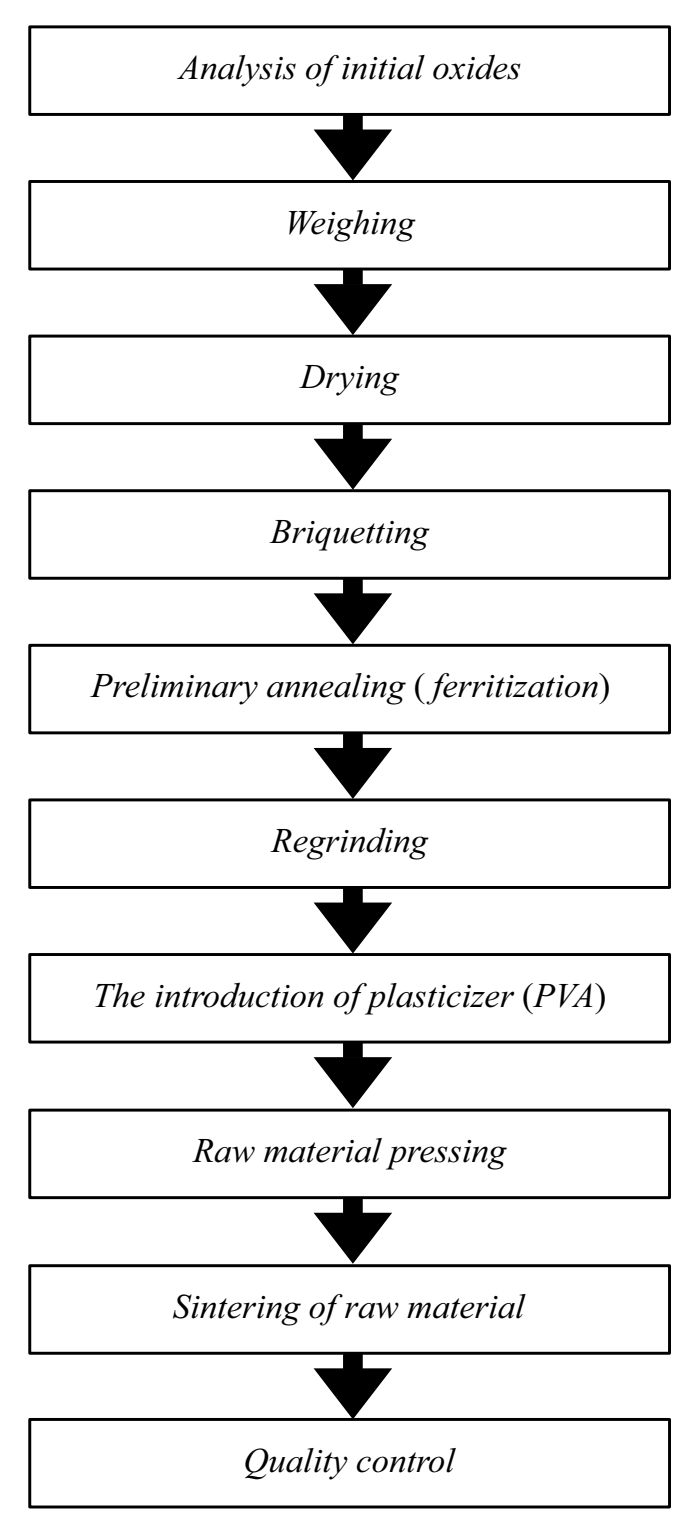

Рис. 1. Технологическая схема получения в работе ферритовшпинелей $\mathrm{Li}_{0.33} \mathrm{Fe}_{2.29} \mathrm{Zn}_{0.21} \mathrm{Mn}_{0.17} \mathrm{O}_{4}$ методом керамической технологии.

$1100^{\circ} \mathrm{C}$. Обычно температура спекания литий-цинковых ферритов-шпинелей выше $950^{\circ} \mathrm{C}[16]$, но на ее снижение могут влиять такие факторы как атмосфера синтеза [17], тип и концентрация интенсифицирующих спекание добавок [18-22], вид и количество замещающих катионов [23-25]. В связи с этим целесообразны попытки провести синтез при такой относительно низкой температуре как $950^{\circ} \mathrm{C}$. Образцы были изготовлены в форме колец с внешним и внутренним диаметрами 16.0 и $7.0 \mathrm{~mm}$ соответственно и высотой $h=5.0-6.0 \mathrm{~mm}$. Для каждого значения температуры спекания было изготовлено и исследовано по пять образцов. Значения результатов измерения усреднялись по пяти измерениям. Характеризацию кристаллической структуры объектов исследования проводили методом рентгенофазового анализа на дифрактометре ДРОН-8 с $\mathrm{Cu} K_{\alpha 1}$-излучением $(\lambda=1.541 \AA)$. Уточнение химического состава полученных ферритов проводилось при использовании метода вторичной ионной масс-спектрометрии. Параметры петли гистерезиса по индукции и полевой спектр магнитной проницаемости в том же диапазоне значений магнитных полей объектов исследования были получены на магнитоизмерительной установке МК-3Э в диапазоне магнитных полей $-400-+400 \mathrm{~A} / \mathrm{m}$.

Комплексная диэлектрическая проницаемость, комплексная магнитная проницаемость и коэффициент отражения на металлической пластине объектов исследования в диапазоне частот $0.01-7.0 \mathrm{GHz}$ регистрировались на установке, состоящей из векторного анализатора цепей Rohde\&Schwarz ZVL и коаксиальной ячейки для измерения комплексных физических констант диэлектрической и магнитной проницаемости твердых изотропных материалов ДМП-2.

\section{2. Результаты эксперимента}

На рис. 2 представлена зависимость магнитной проницаемости $\mu$ от напряженности магнитного поля объектов исследования, полученных при разных температурах спекания. На вставке к рис. 2 показаны петли магнитного гистерезиса.

Кривые магнитной проницаемости имеют характерный для ферритов вид с максимумом. Однако с увеличением температуры спекания с 1000 до $1100^{\circ} \mathrm{C}$ наблюдается тенденция сдвига максимального значения магнитной проницаемости в сторону меньших полей.

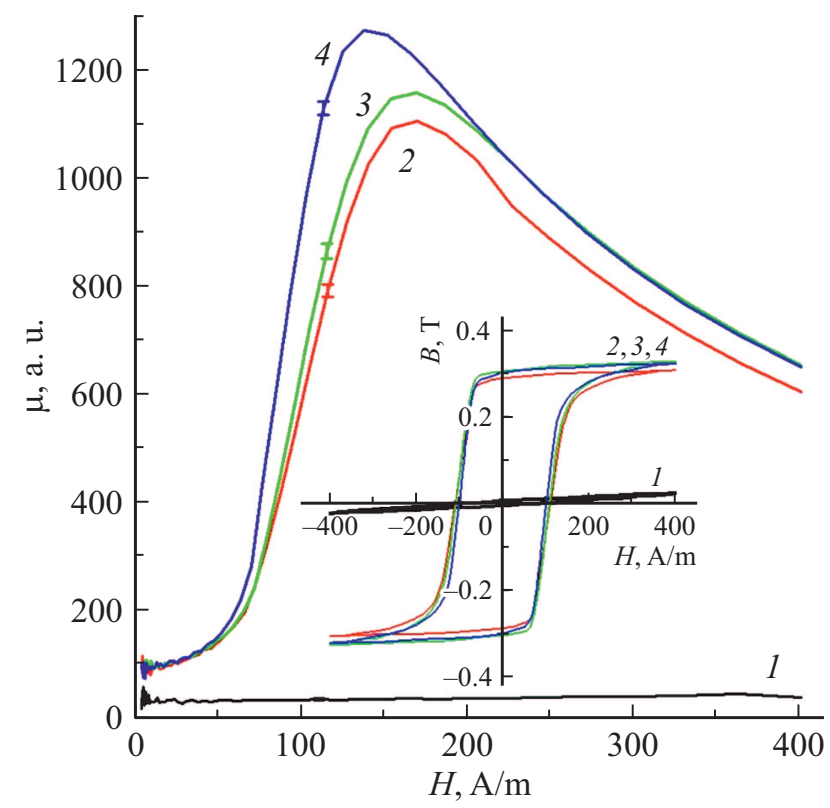

Рис. 2. Зависимость магнитной проницаемости от напряженности магнитного поля для ферритов-шпинелей $\mathrm{Li}_{0.33} \mathrm{Fe}_{2.29} \mathrm{Zn}_{0.21} \mathrm{Mn}_{0.17} \mathrm{O}_{4}$, полученных при разных температурах спекания. Вставка: петли магнитного гистерезиса в координатах $B-H: 1-950,2-1000,3-1050,4-1100^{\circ} \mathrm{C}$. 

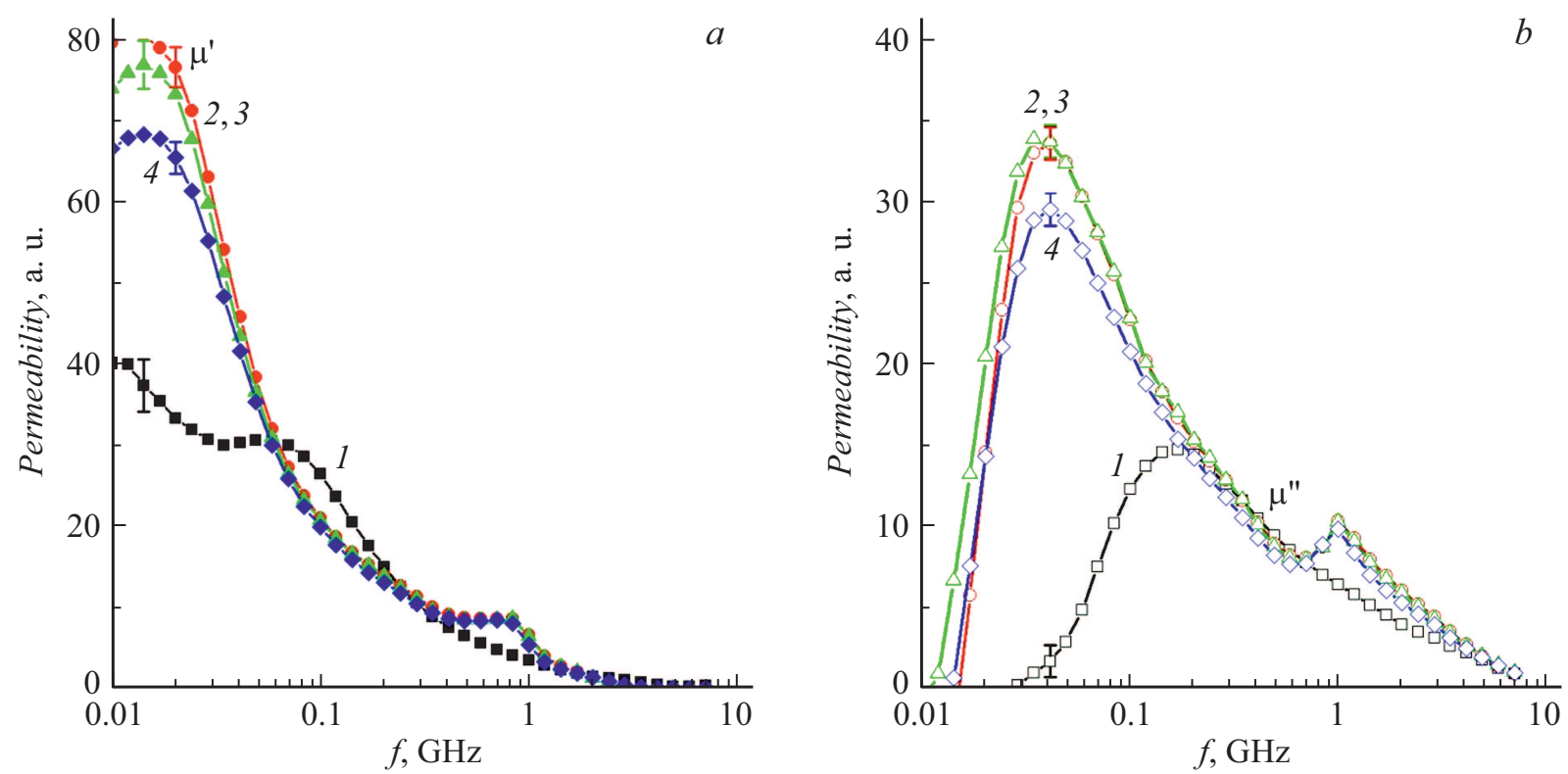

Рис. 3. Частотные спектры действительной $\mu^{\prime}(a)$ и мнимой $\mu^{\prime \prime}(b)$ частей комплексной магнитной проницаемости ферритовшпинелей $\mathrm{Li}_{0.33} \mathrm{Fe}_{2.29} \mathrm{Zn}_{0.21} \mathrm{Mn}_{0.17} \mathrm{O}_{4}$, полученных при разных температурах спекания: $1-950,2-1000,3-1050,4-1100^{\circ} \mathrm{C}$.

Из вставки к рис. 2 видно, что петли гистерезиса для образцов с $T_{s}=1000,1050$ и $1100^{\circ} \mathrm{C}$ очень схожи, обладают высоким значением коэффициента прямоугольности (0.88-0.9). Рост максимальной проницаемости с увеличением температуры спекания может быть связан с увеличением соотношения магнитной фазы (зерен) к немагнитной (межзеренная граница), а, следовательно, возрастанием магнитного потока через образец. По магнитным свойствам образца с $T_{s}=950^{\circ} \mathrm{C}$ можно сказать, что данная температура оказалась недостаточной для процесса спекания.

На рис. 3 представлены частотные спектры действительной $\mu^{\prime}$ (рис. $3, a$ ) и мнимой $\mu^{\prime \prime}$ (рис. $3, b$ ) магнитных проницаемостей образцов, полученных при разных температурах спекания. Можно заметить, что частотная зависимость комплексной магнитной проницаемости в сильной степени зависит от частоты. Для температуры спекания $950^{\circ} \mathrm{C}$ спектр $\mu^{\prime}$ имеет одну область, в которой происходит скачкообразное падение, в то время как для температур спекания $1000-1100^{\circ} \mathrm{C}$ можно выделить две такие области. Спектры $\mu^{\prime \prime}$ характеризуются двумя максимумами для температур спекания $1000-1100^{\circ} \mathrm{C}$ и одним максимумом для $950^{\circ} \mathrm{C}$. Такая частотная зависимость комплексной магнитной проницаемости обусловлена вкладом разных механизмов намагничивания в динамическую проницаемость: движения доменных границ, поворота намагниченности и гиромагнитного спинового вращения [26]. При повышении частоты перечисленные механизмы намагничивания перестают давать вклад в магнитную восприимчивость, что приводит к резкому спаду на спектре действительной магнитной проницаемости. Мнимая часть магнитной проницаемости в области спада действительной части проходит через максимум, частотное положение которого определяет частоту релаксации процесса намагничивания или частоту резонанса. Для поликристаллических ферритов в частотной области $10^{2}-10^{4} \mathrm{MHz}$ выделяют две области изменения динамической магнитной проницаемости: область естественного ферромагнитного резонанса (ЕФMP) $\left(>10^{3} \mathrm{MHz}\right)$ и резонанса доменных границ (РДГ) $\left(<10^{3} \mathrm{MHz}\right)$ [27]. В полученных спектрах $\mathrm{Li}-\mathrm{Mn}-\mathrm{Zn}$ ферритов при температуре спекания выше $950^{\circ} \mathrm{C}$ на спектрах мнимой части магнитной проницаемости можно видеть четкое разделение областей ЕФМР ( 1 GHz) и РДГ $(\sim 0.03 \mathrm{GHz})$. Сдвиг частотного положения максимума $\mu^{\prime \prime}$ и рост абсолютного значения магнитной проницаемости, скорее всего, связан с ростом размеров зерен $[28,29]$. Так как частота релаксации резонанса доменных стенок обратно пропорциональна эффективной массе доменной стенки, а эффективная масса стенки увеличивается с ростом размера зерна [30], происходит сдвиг максимума $\mu^{\prime \prime}$ в сторону низких частот.

На рис. 4 представлены частотные спектры действительной и мнимой частей комплексной диэлектрической проницаемости для образцов с разной температурой спекания. В отличие от магнитных спектров выраженных изменений в области $0.1-10 \mathrm{GHz}$ не наблюдается. Резкий спад на краю диапазона $(<0.01 \mathrm{GHz})$ может быть обусловлен вкладами низкочастотной структурной поляризацией, связанной с ориентацией по полю примесных включений, и дипольной поляризацией. Также нужно отметить малые значения мнимой диэлектрической проницаемости (0.05-0.3 а.u.), что говорит о низком уровне диэлектрических потерь.

На рис. 5 представлены частотные спектры коэффициента отражения $R$ образцов синтезированных ферритов 


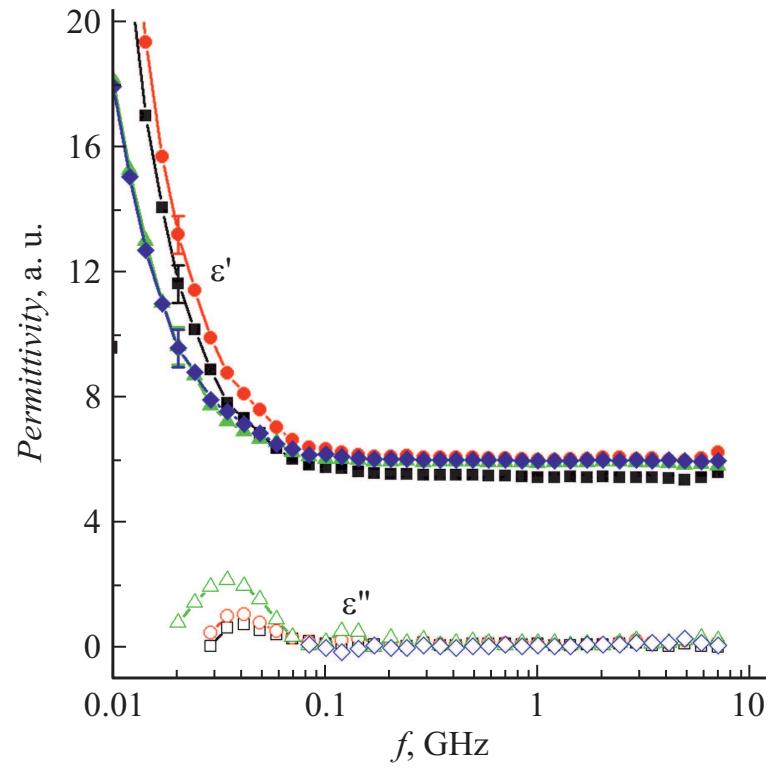

Pис. 4. Частотные спектры действительной и мнимой частей комплексной диэлектрической проницаемости образцов ферритов-шпинелей $\mathrm{Li}_{0.33} \mathrm{Fe}_{2.29} \mathrm{Zn}_{0.21} \mathrm{Mn}_{0.17} \mathrm{O}_{4}$, полученных при разных температурах спекания (графическое обозначение аналогично рис. 3).

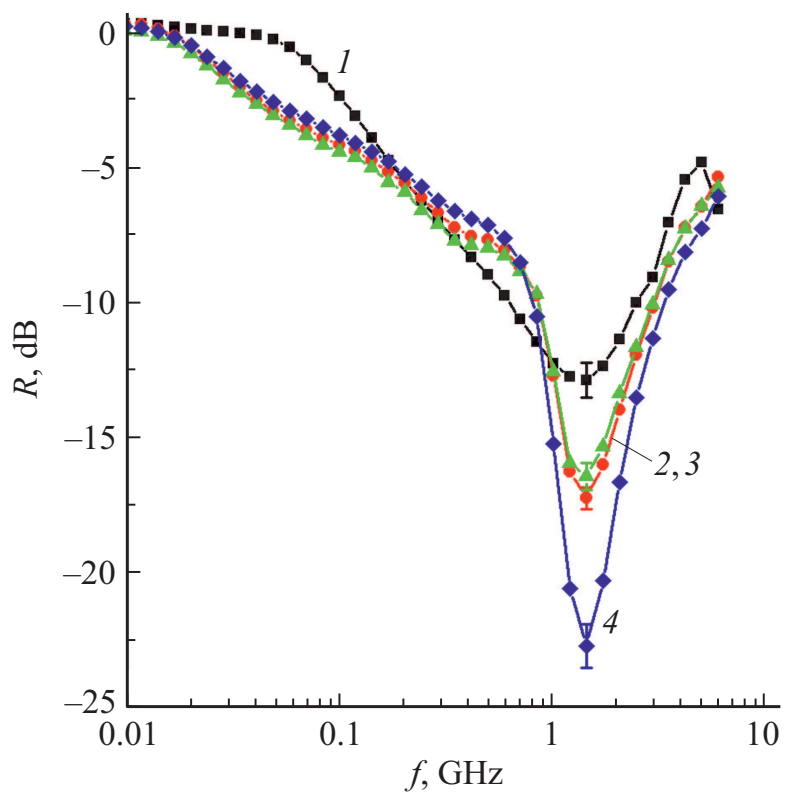

Рис. 5. Частотные спектры коэффициента отражения $R$ образцов ферритов-шпинелей $\mathrm{Li}_{0.33} \mathrm{Fe}_{2.29} \mathrm{Zn}_{0.21} \mathrm{Mn}_{0.17} \mathrm{O}_{4}$, полученных при разных температурах спекания: $1-950(h=5.2 \mathrm{~mm})$; $2-1000(h=5.2 \mathrm{~mm}) ; 3-1050(h=5.5 \mathrm{~mm}) ; 4-1100^{\circ} \mathrm{C}$ $(h=5.0 \mathrm{~mm})$.

на металлической пластине. Следует отметить, что на частотных спектрах отражения $R$ присутствуют минимумы отражения для всех рассматриваемых образцов. Частотное положение данных минимумов лежит в диапазоне $1.3-1.4 \mathrm{GHz}$. Это совпадает с частотным поло- жением пика $\mu^{\prime \prime}$, связанным с ЕФМР. Низкие значения фактора диэлектрических потерь $\varepsilon^{\prime \prime}$ и совпадение частот дисперсии на магнитных спектрах с пиком поглощения говорит об определяющем вкладе магнитных потерь в общие потери в феррите. Также следует отметить почти идентичные спектры для образцов с $T_{s}=1000$ и $1050^{\circ} \mathrm{C}$. Это говорит о возможности получения образцов с заданным спектром. Аппроксимация зависимости пикового поглощения $R_{\min }$ от температуры спекания дает формулу $R_{\min }=41.5-0.058 \cdot T_{s}$. Как можно видеть на рис. 5 , основной минимум отражения $R_{\min }$ уменьшается с увеличением температуры спекания, причем при $T_{s}=950^{\circ} \mathrm{C}$ $R_{\min }=-13 \mathrm{~dB}$, а при $T_{s}=1100^{\circ} \mathrm{C} R_{\min }=-23 \mathrm{~dB}$. При промежуточных температурах спекания значения $R_{\min }$ составляют -17 и $-18 \mathrm{~dB}$, что демонстрирует возможность вариации поглощающих свойств изменением $T_{s}$.

Таким образом, изученный в работе LiZn-ферритшпинель может найти широкое применение в качестве эффективного поглотителя электромагнитных волн в диапазоне частот $1.0-4.0 \mathrm{GHz}\left(R_{\min }=-10--23 \mathrm{~dB}\right)$.

\section{Заключение и выводы}

1. В работе методом керамической технологии синтезированы кольцевые образцы феррита-шпинели $\mathrm{Li}_{0.33} \mathrm{Fe}_{2.29} \mathrm{Zn}_{0.21} \mathrm{Mn}_{0.17} \mathrm{O}_{4}$ при температурах спекания $950,1000,1050$ и $1100^{\circ} \mathrm{C}$.

2. Измерены петли магнитного гистерезиса и статическая магнитная проницаемость $\mu$ и микроволновые (действительная часть диэлектрической проницаемости $\varepsilon^{\prime}$, мнимая часть диэлектрической проницаемости $\mathcal{E}^{\prime \prime}$, действительная часть магнитной проницаемости $\mu^{\prime}$, мнимая часть магнитной проницаемости $\mu^{\prime \prime}$, коэффициент отражения на металлической пластине $R$ ) свойства объектов исследования в зависимости от температуры спекания.

3. Установлено, что оптимальным диапазоном температур спекания для феррита-шпинели $\mathrm{Li}_{0.33} \mathrm{Fe}_{2.29} \mathrm{Zn}_{0.21} \mathrm{Mn}_{0.17} \mathrm{O}_{4}$ является диапазон от 1050 до $1100^{\circ} \mathrm{C}$. Спекание при температуре из указанного диапазона позволяет получить максимальные значения магнитных и радиопоглощающих характеристик.

4. Установлено, что феррит-шпинель $\mathrm{Li}_{0.33} \mathrm{Fe}_{2.29} \mathrm{Zn}_{0.21} \mathrm{Mn}_{0.17} \mathrm{O}_{4}$ является радиопоглощающим материалом в области частот от 0.05 до $7.0 \mathrm{GHz}$. В указанном диапазоне частот материал обладает широкой полосой поглощения, состоящей, по крайней мере, из трех полос с максимумами поглощения $v_{\max 1}=0.1 \mathrm{GHz}, v_{\max 2}=0.37 \mathrm{GHz}$ и $v_{\max 3}=1.34 \mathrm{GHz}$.

5. Феррит-шпинель $\mathrm{Li}_{0.33} \mathrm{Fe}_{2.29} \mathrm{Zn}_{0.21} \mathrm{Mn}_{0.17} \mathrm{O}_{4}$ обладает максимальным поглощением электромагнитного излучения на частоте $v_{\max 3}=1.34 \mathrm{GHz}$, величина поглощения на данной частоте составляет $-22.52 \mathrm{~dB}$.

6. Для феррита-шпинели $\mathrm{Li}_{0.33} \mathrm{Fe}_{2.29} \mathrm{Zn}_{0.21} \mathrm{Mn}_{0.17} \mathrm{O}_{4}$ установлена линейная зависимость величины максимального поглощения электромагнитного излучения $\left(v_{\max }=1.34 \mathrm{GHz}\right)$ от температуры спекания. 
7. Предложены механизмы поглощения электромагнитных волн в полученных объектах исследования.

\section{Финансирование работы}

Исследование выполнено за счет средств гранта Российского научного фонда (соглашение № 19-19-00694 от 06.05.2019 г.).

\section{Конфликт интересов}

Авторы заявляют, что у них нет конфликта интересов.

\section{Список литературы}

[1] Л.И. Рабкин, С.А. Соскин, Б.Ш. Эпштейн. Ферриты. Строение, свойства, технология производства (Энергия, ЛО, 1968)

[2] Л.М. Летюк, В.Г. Костишин, А.В. Гончар. Технология ферритовых материалов магнитоэлектроники (МИСиС, M., 2005)

[3] E.N. Lysenko, S.A. Ghyngazov, A.P. Surzhikov, S.A. Nikolaeva, V.A. Vlasov. Ceram. Int., 45 (2B), 2736 (2019). DOI: 10.1016/j.ceramint.2018.09.061

[4] M. Maisnam, S. Phanjoubam, H.N.K. Sarma, O. Thakur, R. Laishram, C. Prakash. Int. J. Mod. Phys. B, 17 (21), 3881 (2003). DOI: 10.1142/S0217979203021873

[5] A.N. Yusoff, M.H. Abdullah. J. Magn. Magn. Mater., 269 (2), 271 (2004). DOI: 10.1016/S0304-8853(03)00617-6

[6] T. Nakamura, T. Miyamoto, Y. Yamada. J. Magn. Magn. Mater., 256 (1-3), 340 (2003).

DOI: $10.1016 / \mathrm{S} 0304-8853(02) 00698-4$

[7] D.-Y. Kim, Y.-H. Yoon, K.-Y. Jo, G.-B. Jung, Ch-Ch. An. J. Electromagn. Eng. Sci., 16 (3), 150 (2016).

DOI: $10.5515 / J K I E E S .2016 .16 .3 .150$

[8] Н.М. Плетнев, Ю.К. Непочатов, Н.С. Попова, М.А. Пешков. В сб.: Физико-химические аспекты получения материалов из природного и техногенного сырья, под ред. С.А. Шахова (СГУПС, Новосибирск, 2014), с. 29.

[9] Н.М. Плетнев, Ю.К. Непочатов. Огнеупоры и техническая керамика, 4-5, 40 (2015).

[10] Ю.К. Непочатов. Автореф. канд. дисс. (Томск, СГУПС, 2014)

[11] В.Г. Костишин, Р.М. Вергазов, В.Г. Андреев, С.Б. Бибиков, С.В. Подгорная, А.Т. Морченко. Известия ВУЗов. Материалы электронной техники, 4, 18 (2010).

[12] В.Г. Костишин, Р.М. Вергазов, В.Г. Андреев, С.Б. Бибиков, А.Т. Морченко, И.И. Канева, В.Р. Майоров. Известия ВУЗов. Материалы электронной техники, 2, 33 (2011).

[13] В.Г. Костишин, Р.М. Вергазов, С.Б. Меньшова, И.М. Исаев. Российский технол. журн., 8 (6), 87 (2020). DOI: 10.32362/2500-316X-2020-8-6-87-108 [V.G. Kostishin, R.M. Vergazov, S.B. Menshova, I.M. Isaev. Russ. Technol. J., 8 (6), 87 (2020). DOI: 10.32362/2500-316X-2020-8-6-87-108]

[14] В.Г. Костишин, Р.М. Вергазов, С.Б. Меньшова, И.М. Исаев, А.В. Тимофеев. Заводская лаборатория. Диагностика материалов, 87 (1), 30 (2021). DOI: 10.26896/1028-6861-2021-87-1-30-34

[15] P. Baba, G. Argentina, W. Courtney, G. Dionne, D. Temme. IEEE Trans. Magn., 8 (1), 83 (1972).

DOI: $10.1109 /$ TMAG.1972.1067269
[16] Y. Guo, J. Zhu, H. Li. Ceram. Int. In Press, Available online 15 December 2020. DOI: 10.1016/j.ceramint.2020.12.034

[17] M. Arana, P.G. Bercoff, S.E. Jacobo. Proced. Mater. Sci., 1, 620 (2012). DOI: 10.1016/j.mspro.2012.06.084

[18] Y. Yang, H. Zhang, J. Li, F. Xu, G. Gan, D. Wen. Ceram. Int., 44 (9), 10545 (2018). DOI: 10.1016/j.ceramint.2018.03.076

[19] H. Su, Q. Luo, Y. Li, H. Zhang, X. Tang. J. Magn. Magn. Mater., 469, 419 (2019). DOI: 10.1016/j.jmmm.2018.09.009

[20] F. Xie, L. Jia, F. Xu, J. Li, G. Gan, H. Zhang. Ceram. Int., 44 (11), 13122 (2018). DOI: 10.1016/j.ceramint.2018.04.134

[21] Q. Luo, H. Su, X. Tang, Z. Xu, Y. Li, Y. Jing. Ceram. Int., 44 (13), 16005 (2018). DOI: 10.1016/j.ceramint.2018.06.035

[22] G. Gan, D. Zhang, Q. Zhang, G. Wang, X. Huang, Y. Yang, Y. Rao, J. Li, F. Xu, X. Wang, R.T. Chen, H. Zhang. Ceram. Int., 45 (9), 12035 (2019). DOI: $10.1016 /$ j.ceramint.2019.03.098

[23] Z. Noreen, I. Ahmad, F. Siddiqui, A. Ziya, T. Abbas, H. Bokhari. Ceram. Int., 43 (14), 10784 (2017). DOI: $10.1016 /$ j.ceramint.2017.05.092

[24] V. Manikandan, F. Tudorache, L. Petrila, R.S. Mane, V. Kuncser, B. Vasile, D. Morgan, S. Vigneselvan, A. Mirzaei. J. Magn. Magn. Mater., 474, 563 (2019). DOI: $10.1016 /$ j.jmmm.2018.11.072

[25] M.N. Akhtar, M.A. Khan. J. Magn. Magn. Mater., 460, 268 (2018). DOI: 10.1016/j.jmmm.2018.03.069

[26] T. Tsuoka. J. Appl. Phys., 93 (5), 2789 (2003). DOI: $10.1063 / 1.1542651$

[27] Боков В.А. Физика магнетиков (ФТИ им. А.Ф. Иоффе РАН, СПб., 2002)

[28] C. Clausell, A. Barba, L. Nuño, J. Carlos Jarque. Ceram. Int., 42 (3), 4256 (2016). DOI: 10.1016/j.ceramint.2015.11.101

[29] Md.D. Rahaman, K.K. Nahar, M.N.I. Khan, A.K.M. Akther Hossain. Phys. B, 481, 156 (2016). DOI: $10.1016 /$ j.physb.2015.11.008

[30] Гуревич А.Г. Магнитные колебания и волны (Наука, М., 1994) 